\title{
Analisis Nilai Tambah Usaha Pengolahan Ikan Manyung Asap Di Kabupaten Demak
}

\author{
Shofia Nur Awami1)* \\ Eka Dewi Nurjayanti2) \\ Endah Subekti ${ }^{3)}$ \\ 1),2),3)Program Studi Agribisnis Fakultas Pertanian Universitas Wahid Hasyim Semarang \\ *email: shofifaperta@unwahas.ac.id \\ Diterima: Juni 2019; Disetujui: Agustus 2019; Dipublish: Oktober 2019
}

\begin{abstract}
Abstrak
Salah satu cara pengolahan produk perikanan secara tradisional adalah pengasapan. Pengolahan hasil perikanan mempunyai tujuan diantaranya meningkatkan nilai tambah. Penelitian ini bertujuan untuk mengetahui nilai tambah usaha pengolahan ikan manyung asap, tingkat kelayakan usaha dan keuntungan usaha pengolahan ikan manyung asap, dan faktor yang mempengaruhi nilai tambah usaha pengolahan ikan manyung asap. Analisis yang digunakan dalam penelitian ini menggunakan analisis nilai tambah metode Hayami, analisis keuntungan serta kelayakan dan analisis regresi berganda. Hasil penelitian menunjukkan usaha pengolahan ikan manyung asap memberikan nilai tambah sebesar Rp. 4.042/kg. Ratarata penerimaan per siklus produksi sebesar Rp. 2.773.000, dan rata-rata keuntungan Rp.251.908. RC ratio 1,154, BEP produksi 16,442 kg, dan BEP penerimaan Rp.358.604. Faktor yang mempengaruhi nilai tambah pengolahan ikan manyung asap di Kabupaten Demak adalah jumlah tenaga kerja, jumlah bahan baku, usia pengolah, dan harga output.
\end{abstract}

Kata Kunci: Nilai tambah, Ikan manyung asap, BEP, Penerimaan.

\begin{abstract}
Traditional methods of processing fishery products are fumigation. Processing of fishery products has objectives including increasing added value. This research aimed to determine added value of smoked manyung fish processing business, the level of feasibility and the profit of smoked manyung fish processing business, and the factors that influenced added value of smoked manyung fish processing business. This research covered analysis methods several including, the added value analysis according Hayami, et all (1987), the profit and feasibility analysis, and multiple linear regression analysis. The research showed that the added value of processing smoked manyung fish business is Rp. 4,042 per kilogram. The average total revenue for smoked manyung fish processing per production cycle of Rp.2,773,000, and average profit of Rp.251,908. Furthermore, $R C$ ratio value of 1.154, units BEP of processing smoked manyung fish amount to 16,442 kilogram and the revenue value BEP is Rp.358,604. Added value of processed smoked manyung fish in Demak District were influenced by several factors including; the amount of labor, the amount of raw materials, the processor's age, and output prices.
\end{abstract}

Keywords: Added value, Smoked manyung fish, BEP, Revenue.

\section{PENDAHULUAN}

Wilayah Kabupaten Demak

sebelah Utara, berbatasan dengan wilayah perairan Pantai Utara Jawa, yaitu mencakup wilayah disepanjang
15 desa yang berada di 4 wilayah kecamatan yakni: Kecamatan Sayung, Karangtengah, Bonang, dan Wedung. Berbagai jenis ikan laut yang ditangkap di Kabupaten Demak tidak kurang dari 
300 ton tiap tahunnya. Menurut jenis ikan laut basah yang dijual di 2 TPI, produksi ikan tertinggi adalah ikan kembung sebesar 1.287.554 kg dengan nilai produksi sebesar Rp. 16.697.838.000, selanjutnya ikan teri sebesar $308.556 \mathrm{~kg}$ dengan nilai produksi sebesar Rp.3.030.128.000,(Kementerian Kelautan dan Perikanan, 2011). Adapun produksi ikan basah yang dijual di 2 TPI, yaitu di Morodemak dengan produksi sebesar 2.094.675 kg dengan nilai produksi sebesar Rp.31.416.675.000,-, serta TPI Wedung dengan produksi sebesar $84.013 \mathrm{~kg}$ dengan nilai produksi Rp. 671.414.000,- (BPS, 2016). Peran kegiatan pengolahan hasil perikanan menjadi sangat penting, dikarenakan produk perikanan termasuk produk yang cepat membusuk jika tidak segera diolah/dikonsumsi. Kegiatan pengolahan hasil perikanan juga merupakan salah satu subsistem agribisnis yang mempunyai peluang besar dalam meningkatkan nilai tambah hasil produk perikanan. Salah satu proses pengawetan ikan yang popular adalah dengan pengasapan. Adapun kegiatan selain pengasapan dapat berupa pemindangan, pengasinan pengeringan ataupun fermentasi.

Menurut Sulistijowati, (2011) pengasapan (smoking) diartikan untuk penyerapan bermacam-macam senyawa kimia yang berasal dari asap kayu ke dalam daging ikan, disertai dengan setengah pengeringan dan biasanya didahului dengan proses penggaraman. Proses pengasapan sering dikombinasikan dengan pengeringan sinar matahari atau didahului perlakuan penggaraman. Pengasapan meliputi seluruh proses yang dimulai dari tahap persiapan bahan mentah (ikan segar) sampai ke pengasapan terakhir yang mengakibatkan perubahan pada bahan mentah seperti perubahan warna, flavour, dan tekstur ikan.

Pengasapan ikan merupakan salah satu usaha pengolahan hasil perikanan yang potensial di Kabupaten Demak. Salah satu wilayah di Kabupaten Demak yang terkenal dengan ikan asapnya adalah Desa Wonosari Kecamatan Bonang. Pada tahun 2000 didirikan kelompok usaha bersama yang diberi nama "ASAP INDAH" yang diketuai oleh Bapak Juyamin. Meskipun sudah 18 tahun berdiri dan kegiatan usaha pengasapan berjalan, menurut penelitian Shoimah pada tahun 2013, terkait perencanaan pengelolaan lingkungan di sentra pengasapan ikan Desa Wonosari guna semakin meningkatkan kualitas produk dan memberikan keamanan bagi konsumen, menyatakan masih perlu adanya suatu tata kelola yang baik untuk membuat sentra pengasapan ikan yang memenuhi persyaratan industri pengolahan hasil perikanan. Sistem Manajemen Lingkungan merupakan salah satu solusi yang mungkin diterapkan walaupun memerlukan waktu yang cukup lama. Kondisi sentra pengasapan tersebut relatif sudah cukup baik jika dibandingkan dengan kondisi sebelumnya. Pembuatan ikan 
asap tersentra dalam satu lokasi. Sebelumnya kegiatan pengasapan ikan dilakukan di rumah pengolah masingmasing. Sentra pengasapan "ASAP INDAH" dibangun dalam rangka pengembangan sentra pengolahan ikan di Jawa Tengah, oleh Kementerian Kelautan dan Perikanan melalui Dirjen Pengolahan dan Pemasaran Hasil Perikanan yang bekerja sama dengan Pemerintah Kabupaten Demak membangun tempat pengasapan ikan yang tersentra di satu lokasi serta terpadu.

Sementara dalam pengolahannya, bahan baku ikan segar yang diolah menjadi ikan asap di datangkan dari daerah sekitar seperti Kecamatan Wedung atau dari TPI Juwana, Pati. Jenis ikan yang bisa di asap antara lain ikan manyung (N.Thalassinus), ikan pari (Aetobatus spp.), ikan tongkol (Euthynnus allecterates), ikan lele (Clarias batrachus) dan ikan bandeng (Chanos chanos). Rata-rata jumlah pengasapan ikan yang dilakukan oleh satu pengolah berkisar antara $80 \mathrm{~kg}$ sampai $200 \mathrm{~kg}$ per hari. Pengadaan bahan baku ikan segar diperoleh melalui pedagang ikan segar yang datang ke desa.

Rata-rata proses pengasapan ikan manyung menggunakan bahan bakar seperti limbah kelapa mulai dari sabut, tempurung kelapa serta serbuk gergaji atau tongkol/janggel jagung. Kebanyakan dari pengolah yang berada di sentra "ASAP INDAH" menggunakan tongkol/janggel jagung. Proses kegiatan pengasapan biasanya dimulai sekitar jam 12.00 (untuk persiapan) hingga 16.00 WIB, yang sebelumnya diawali dengan kegiatan persiapan seperti menerima bahan baku ikan segar dari pedagang ikan yang datang, pembelahan dan pengirisan ikan, pembersihan ikan sekaligus perendaman ikan (dengan penambahan jeruk nipis), penirisan, penusukan irisan daging ikan dengan bambu (persiapan sebelum diasap), baru proses pengasapan. Dalam pemasarannya, setiap pengolah ikan asap tersebut mempunyai pelanggan pedagang masing-masing, berkisar 2-3 orang, bahkan ada pengolah yang mempunyai pelanggan pedagang dari luar kota yang datang 3-4 hari sekali. Selain itu pengolah juga melayani konsumen akhir yang datang membeli secara langsung. Sementara, jika ikan asap masih tersisa atau tidak terjual semuanya, pengolah akan menjual sendiri ke pasar tradisional keesokan harinya.

Berdasarkan uraian tersebut, maka tujuan penelitian ini diantaranya untuk mengetahui: 1). besarnya nilai tambah dari usaha pengolahan ikan manyung asap, 2). tingkat keuntungan dan kelayakan usaha olahan ikan manyung asap, dan 3). faktor yang mempengaruhi nilai tambah pada usaha olahan ikan manyung asap di Kabupaten Demak.

\section{METODE PENELITIAN}

Penelitian ini merupakan penelitian deskriptif analitis. Penelitian dilaksanakan pada periode produksi di bulan Maret hingga April tahun 2018. Penentuan lokasi ditentukan dengan 
cara pengambilan sengaja/purposive, yaitu dipilih Kabupaten Demak, sebagai salah satu daerah penghasil olahan ikan di Jawa Tengah serta mempunyai sentra usaha pengolahan ikan, seperti halnya di Desa Wonosari Kecamatan Bonang yang terdapat pengolahan ikan asap (Sentra Pengasapan "Asap Indah"). Responden yang dilibatkan dalam penelitian sejumlah 70 pengolah ikan manyung asap.

\section{Analisis Data}

Data yang digunakan dalam penelitian merupakan data primer dan sekunder. Analisis data menggunakan analisis nilai tambah metode Hayami (1987). Selain itu juga menggunakan analisis keuntungan, yang terlebih dahulu dengan menghitung tingkat biaya (Tasman dan Aima, 2013), penerimaan, dan pendapatan (Soekartawi, 2002). Analisis kelayakan melalui RC ratio serta BEP, sesuai dengan rumusan (Suratiyah, 2015).

$\pi=\mathrm{TR}-\mathrm{TC}$ eksplisit + implisit $\ldots \ldots \ldots \ldots \ldots \ldots . . . . .1)$

$\pi=\mathrm{TR}-(\mathrm{TVC}+\mathrm{TFC})$ eksplisit + implisit $\ldots . .2)$

$\pi=$ Py.Y $-($ Px. X + TFC ) eksplisit + implisit 3$)$

Keterangan:

$\pi=$ Profit

$\mathrm{TR}=$ Total Revenue

TC eksplisit +implisit $=$ Total cost eksplisit + implisit (Biaya total eksplisit + implisit)

$\mathrm{TFC}=$ Total Fixed Cost

TVC $=$ Total Variabel Cost

Py = Harga Output

$\mathrm{Y}=$ Jumlah Output

$\mathrm{Px}=$ Harga Input

$\mathrm{X}=$ Jumlah Input
Analisis RC ratio usaha pengasapan ikan manyung dengan rumusan:

$\mathrm{RC}$ ratio $=\mathrm{TR} / \mathrm{TC}$

$\mathrm{RC}$ ratio $=\mathrm{Y} . \mathrm{Py} /(\mathrm{TFC}+\mathrm{TVC}) \ldots \ldots \ldots . . .5)$

Keterangan:

$\mathrm{TR}=$ Total Revenue

$\mathrm{TC}=$ Total Cost

$\mathrm{Y}=$ Total Produksi

$\mathrm{Py}=$ Harga produksi per unit

$\mathrm{TFC}=$ Total Fixed Cost

TVC $=$ Total Variable Cost

Kriteria R/C sebagai berikut:

$\mathrm{R} / \mathrm{C}>1$, usaha pengasapan ikan manyung efisien dan menguntungkan $\mathrm{R} / \mathrm{C}=1$, usaha pengasapan ikan manyung berada pada BEP

$\mathrm{R} / \mathrm{C}<1$, usaha pengasapan ikan manyung tidak efisien dan merugi

Analisis Break Event Point (BEP) meliputi BEP penerimaan (Rp), BEP produksi (unit), dengan formula sebagai berikut:

BEP dalam nilai penerimaan (Rp):

$B E P=\frac{F C}{(1-V C / \text { penjualan })}=R p$

BEP dalam unit penjualan/produksi (unit) :

$$
B E P=\frac{F C}{(p-W C / \text { wnit })}=\text { Unit...........7) }
$$

Keterangan :

$\mathrm{FC}=$ Biaya tetap

$\mathrm{VC}=$ Biaya variabel

$\mathrm{TC}=$ Total cost

$\mathrm{P}=$ Harga produksi $(\mathrm{Rp} / \mathrm{kg})$

$\mathrm{Q}=\operatorname{Jumlah} \operatorname{produk}(\mathrm{Kg} /$ unit/bulan)

Sementara untuk mengetahui faktor yang mempengaruhi nilai tambah usaha pengolahan ikan manyung asap menggunakan analisis regresi linier berganda regresi linier berganda 
sesuai ketentuan dalam Widarjono (2009).

\section{HASIL DAN PEMBAHASAN}

\section{Karakteristik Pengolah Ikan \\ Manyung Asap}

Kondisi demografi pengolah ikan manyung asap yang dimaksud dalam penelitian ini meliputi umur dan jumlah anggota keluarga. Sementara karakteristik sosial ekonomi pengolah ikan manyung asap meliputi kondisi/tingkat pendidikan, lama usaha/pengalaman. Karakteristik tersebut terperinci dalam Tabel 1. Rata-rata pengolah ikan manyung asap termasuk dalam usia produktif. Tingkat pendidikan rata-rata sudah menempuh pendidikan setingkat SMP. Rata-rata pengalaman menjalankan usaha ikan asap 4 hingga 6 tahun.

Tabel 1. Karakteristik Umur, Tingkat Pendidikan, Lama Mengelola Usaha/

Pengalaman serta Jumlah Anggota Keluarga Pengolah Ikan Asap.

\begin{tabular}{|c|c|c|c|}
\hline No & Uraian & & $\begin{array}{l}\text { Pengolah Ikan } \\
\text { Manyung Asap }\end{array}$ \\
\hline \multirow[t]{4}{*}{1} & Umur & $30-39$ & $9(12,86)$ \\
\hline & & $40-49$ & $46(65,71)$ \\
\hline & & $50-59$ & $15(21,43)$ \\
\hline & & Jumlah & $70(100)$ \\
\hline \multirow[t]{4}{*}{2} & Tingkat Pendidikan & SD & - \\
\hline & & SMP & $63(90$ \\
\hline & & $\geq$ SMA & $7(10)$ \\
\hline & & Jumlah & $70(100)$ \\
\hline \multirow[t]{4}{*}{3} & Lama Usaha & $1-3$ & $14(20,00)$ \\
\hline & & $4-6$ & $50(71,43)$ \\
\hline & & $7-9$ & $6(8,67)$ \\
\hline & & Jumlah & $70(100)$ \\
\hline \multirow[t]{4}{*}{4} & Anggota & $1-2$ & $2(2,86)$ \\
\hline & Keluarga & $3-4$ & $47(67,14)$ \\
\hline & & $\geq 5$ & $21(30,00)$ \\
\hline & & Jumlah & $70(100)$ \\
\hline
\end{tabular}

Sumber: Analisis Data Primer, 2018.

Analisis Nilai Tambah Usaha Pengolahan Ikan Manyung Asap

Menurut Hayami et al. (1987) menyatakan bahwa nilai tambah adalah selisih antara komoditas yang mendapat perlakuan pada tahap tertentu dan nilai korbanan yang digunakan selama proses berlangsung. Proses pengolahan ikan manyung segar menjadi ikan asap menghasilkan dua macam produk yaitu ikan asap iris (bagian badan) serta kepala ikan (kepala manyung). Ikan asap iris dijual dengan rata-rata harga Rp. 2.000 per satuan iris dan kepala yang diasap, dijual dengan satuan kilogram dihargai sekitar Rp. 30.000 per kilogram. Guna memudahkan perhitungan nilai tambah, dalam penelitian ini jumlah output yang dihasilkan merupakan hasil konversi. Pengkonversian perlu dilakukan dalam perhitungan, 
dikarenakan dalam kondisi riil, pengolah ikan asap membeli bahan baku ikan manyung segar dalam satuan kilogram, sementara menjual ikan asap dalam satuan iris (untuk badan ikan) dan kilogram (untuk kepala ikan).

Berdasarkan Tabel 2, terlihat bahwa rata-rata per siklus produksi, pengolah ikan manyung asap menggunakan bahan baku ikan manyung segar sebanyak 100 kilogram dengan harga beli Rp. 22.000 per kilogram. Rata-rata harga bahan baku ikan manyung segar berkisar Rp 20.000 hingga Rp 22.000 per kilogram. Usaha pengolahan ikan manyung asap memberikan nilai tambah sebesar Rp. $4.042 / \mathrm{kg}$ dengan rasio nilai tambah 14,58\%. Berdasarkan hasil analisis juga diperoleh marjin dari masingmasing proses pengolahan. Marjin merupakan selisih antara nilai output dengan harga bahan baku ikan. Marjin ini kemudian didistribusikan menjadi imbalan tenaga kerja, sumbangan input lain, dan keuntungan pengolah.

Nilai tambah diperoleh dengan pengurangan nilai produk dengan harga bahan baku dan sumbangan input lain per kilogram. Nilai tambah dari proses pengolahan ikan manyung segar menjadi ikan manyung asap adalah sebesar Rp. 4.042 per kilogram, artinya setiap 1 kilogram ikan manyung segar yang diolah menjadi ikan asap akan menciptakan nilai tambah sebesar Rp. 4.042. Nilai tambah tersebut merupakan nilai tambah kotor bagi pengolah, karena belum dikurangi imbalan bagi tenaga kerja.

Berdasarkan Tabel 2, secara terperinci nilai tambah kotor masih mengandung imbalan tenaga kerja yaitu sebesar Rp. 2.299 dengan persentase imbalan tenaga kerja terhadap nilai tambah sebesar 78,63 persen. Besarnya keuntungan yang diperoleh dari proses pengolahan ikan manyung asap adalah Rp. 1.743 per kg dengan tingkat keuntungan sebesar 5,99 persen dari nilai output. Nilai keuntungan tersebut merupakan selisih antara nilai tambah dengan imbalan tenaga kerja. Dengan demikian dapat dikatakan bahwa keuntungan ini merupakan keuntungan bersih yang diterima pengolah olahan ikan asap karena sudah dikurangi dengan imbalan tenaga kerja.

Pada usaha pengolahan ikan manyung asap, marjin total dari proses pengolahan ikan manyung segar menjadi ikan asap adalah sebesar Rp. 5.009 per kilogram. Marjin yang didistribusikan untuk tenaga kerja adalah Rp. 2.598 per kilogram atau sebesar 51,87 persen. Marjin untuk sumbangan input lain adalah Rp. 1.034 per kilogram atau sebesar 20,64 persen, serta marjin untuk keuntungan sebesar Rp. 1.377 per kilogram atau 27,49 persen. 
Tabel 2. Rata-rata Nilai Tambah Pengolahan Ikan Manyung Asap per Siklus Periode Produksi.

\begin{tabular}{|c|c|c|c|}
\hline No & Variabel & Rumus & $\begin{array}{c}\text { Usaha Pengolahan } \\
\text { Ikan Asap }\end{array}$ \\
\hline \multicolumn{4}{|c|}{ Output, Input, Harga } \\
\hline 1 & Output (Kg/PP) & A & 96,96 \\
\hline 2 & Input bahan baku (Kg/PP) & B & 100 \\
\hline 3 & Tenaga kerja (HOK/ periode produksi) & $\mathrm{C}$ & 1,91 \\
\hline 4 & Faktor konversi & $\mathrm{D}=\mathrm{A} / \mathrm{B}$ & 0,97 \\
\hline 5 & Koefisien Tenaga kerja (HOK/kg) & $\mathrm{E}=\mathrm{C} / \mathrm{B}$ & 0,021 \\
\hline 6 & Harga output (Rp/kg) & $\mathrm{F}$ & 27.796 \\
\hline 7 & Upah Tenaga kerja (Rp/HOK) & G & 111.254 \\
\hline \multicolumn{4}{|c|}{ Pendapatan dan Nilai Tambah } \\
\hline 8 & Harga bahan baku (Rp/Kg) & $\mathrm{H}$ & 22.000 \\
\hline 9 & Harga input lain (Rp/kg) & I & 966,36 \\
\hline 10 & Nilai output (Rp/kg) & $\mathrm{J}=\mathrm{D} \times \mathrm{F}$ & $27.008,68$ \\
\hline \multirow[t]{2}{*}{11} & a. Nilai tambah (Rp/kg) & $\mathrm{K}=\mathrm{J}-\mathrm{H}-\mathrm{I}$ & $4.042,32$ \\
\hline & b. Rasio nilai Tambah (\%) & $\mathrm{L} \%=\mathrm{K} / \mathrm{J} \times 100 \%$ & 14,58 \\
\hline \multirow[t]{2}{*}{12} & a. Pendapatan Tenaga kerja $(\mathrm{Rp} / \mathrm{kg})$ & $M=E \times G$ & $2.299,29$ \\
\hline & b. Pangsa tenaga kerja (\%) & $\mathrm{N} \%=\mathrm{M} / \mathrm{K} \times 100 \%$ & 78,63 \\
\hline \multirow[t]{3}{*}{13} & a. Keuntungan (Rp/kg) & $\mathrm{O}=\mathrm{K}-\mathrm{M}$ & $1.743,63$ \\
\hline & b. Tingkat keuntungan (\%) & $\mathrm{P} \%=0 / \mathrm{J} \times 100 \%$ & 5,98 \\
\hline & Balas jasa untuk Faktor produksi & & \\
\hline \multirow[t]{4}{*}{14} & Marjin (Rp/kg) & $\mathrm{Q}=\mathrm{J}-\mathrm{H}$ & $5.008,68$ \\
\hline & a. Pendapatan Tenaga kerja (\%) & $\mathrm{R} \%=\mathrm{M} / \mathrm{Q} \times 100 \%$ & 51,87 \\
\hline & b. Modal (sumbangan input lain) (\%) & $\mathrm{S} \%=\mathrm{I} / \mathrm{Q} \times 100 \%$ & 20,64 \\
\hline & c. Keuntungan pengolah (\%) & $\mathrm{T} \%=0 / \mathrm{Q} \times 100 \%$ & 27,49 \\
\hline
\end{tabular}

Sumber: Analisa Data Primer, 2018.

\section{Analisis Kelayakan Usaha Olahan Ikan Manyung Asap}

Faktor yang mempengaruhi keuntungan usaha olahan ikan manyung asap adalah penerimaan (TR) dan biaya usaha olahan ikan (TC). Penerimaan pada usaha olahan ikan manyung asap merupakan nilai produksi yang diperoleh dari perkalian antara jumlah produksi olahan ikan yang dihasilkan dengan harga produksi olahan ikan yang dihasilkan. Adapun analisis biaya, penerimaan, pendapatan, keuntungan, RC dan BEP pada usaha pengolahan ikan manyung asap per siklus periode produksi dapat dilihat pada Tabel 3. 
Tabel 3. Rata-rata Penerimaan, Biaya dan Keuntungan Pengolah Usaha Pengolahan Ikan Manyung Asap Per siklus Periode Produksi di Kabupaten Demak

\begin{tabular}{|c|c|c|}
\hline No & Uraian & $\begin{array}{c}\text { Usaha Pengolahan } \\
\text { Ikan Asap }\end{array}$ \\
\hline \multirow[t]{10}{*}{1} & Penerimaan (Terdapat 2 produk) & \\
\hline & a. Irisan (badan ikan) & \\
\hline & - Produksi (iris/potong) & 978,07 \\
\hline & - $\quad$ Harga jual (Rp) & 2.000 \\
\hline & - $\quad$ Nilai produksi (Rp) & 1.956 .714 \\
\hline & b. Kepala Ikan & \\
\hline & - $\quad$ Produksi $(k g)$ & 27,23 \\
\hline & - $\quad$ Harga jual (Rp) & 30.000 \\
\hline & - $\quad$ Nilai produksi $(\mathrm{Rp})$ & 811.714 \\
\hline & c. Total nilai produksi (Rp) & 2.773 .000 \\
\hline \multirow[t]{22}{*}{2} & Biaya usaha pengolahan ikan asap & \\
\hline & a. Biaya tetap & \\
\hline & - Penyusutan alat (Rp) & 7.631 \\
\hline & - Biaya Bunga modal investasi & 23.015 \\
\hline & - Biaya sewa tempat & 1.389 \\
\hline & - Biaya air & 5.000 \\
\hline & Jumlah biaya tetap (a) & 37.049 \\
\hline & b. Biaya variabel & \\
\hline & - Bahan Baku (Ikan segar) & 2.200 .000 \\
\hline & - Biaya janggel/tempurung & 35.871 \\
\hline & - Pembelian bambu & 19.136 \\
\hline & - Biaya Transportasi & 15.600 \\
\hline & - Biaya Listrik & 10.000 \\
\hline & - Tenaga kerja LK & 105.286 \\
\hline & - Tenaga kerja DK & 100.642 \\
\hline & Jumlah biaya variabel (b) & 2.487 .178 \\
\hline & Jumlah biaya $(a+b)$ & 2.521 .092 \\
\hline & Pendapatan (Rupiah) & 375.566 \\
\hline & Keuntungan (Rupiah) & 251.908 \\
\hline & $\mathrm{RC}$ ratio & 1,154 \\
\hline & BEP per Unit (Kg) & 16,442 \\
\hline & BEP penerimaan (Rp) & 358.504 \\
\hline
\end{tabular}

Sumber: Analisis Data Primer, 2018.

Biaya usaha olahan ikan manyung asap adalah perkalian antara jumlah faktor produksi yang meliputi biaya tetap (penyusutan alat produksi, sewa tempat dimana masing-masing pengolah dikenakan membayar sewa tempat per unit sebesar Rp. 500.000 per tahun, dan biaya penggunaan air, rata-rata sebesar Rp. 150.000 per bulan) dan biaya variabel (biaya pembelian ikan segar, bahan bakar: tongkol atau janggel jagung/ tempurung kelapa, biaya transportasi dan sebagainya). Rata-rata total biaya yang dikeluarkan pengolah ikan manyung asap per periode produksi 
sebesar Rp. 2.521.092, yang terdiri dari rata-rata biaya tetap sebesar Rp.37.049 dan biaya variabel Rp. 2.487.178. Adapun hasil penelitian yang dilakukan Yusroni (2009) menyatakan bahwa pada usaha pengolahan/pengasapan ikan di Kelurahan Bandarharjo Kota Semarang, biaya produksi terbesar berada pada pengolahan/pengasapan ikan manyung jika dibandingkan dengan beberapa pengasapan ikan jenis lainnya, seperti ikan pari dan tongkol. Besar kecilnya biaya produksi dipengaruhi oleh: harga bahan baku, skala produksi, biaya transportasi, upah buruh dan biaya lain-lain. Keuntungan yang diperoleh oleh masing-masing pengusaha ikan asap di Kelurahan Bandarharjo juga bervariasi, tergantung pada besar kecilnya nilai produksi total dan biaya produksi total.

Nilai RC ratio untuk usaha pengolahan ikan manyung asap adalah sebesar 1,154, dengan demikian nilainya lebih dari 1 berarti usaha pengolahan ikan manyung menjadi ikan asap menguntungkan dan layak untuk dilaksanakan. Nilai 1,154 bermakna setiap pengeluaran Rp.1, pengusaha mendapatkan penerimaan sebesar Rp. 1,154.

Sementara, berdasarkan penelitian Sulistyowati (2010), pengasapan ikan manyung di usaha pengasapan "Mina Asri" Kecamatan Semarang Utara Kota Semarang, diperoleh RC ratio sebesar 1,24. Hasil dari perhitungan BEP unit untuk usaha pengolahan ikan asap adalah sebesar 16,442 kilogram, artinya usaha pengolahan ikan asap ini akan mencapai titik impas apabila produksi mencapai 16,442 kilogram.

Sedangkan BEP penerimaan/ nilai produksi adalah sebesar Rp. 358.504, artinya penerimaan untuk mencapai titik impas adalah sebesar Rp. 358.504

\section{Faktor Yang Mempengaruhi Nilai Tambah Usaha Pengolahan Ikan Manyung Asap}

Nilai tambah yang digunakan adalah nilai tambah total yang diperoleh dari proses pengolahan ikan manyung segar menjadi ikan manyung asap oleh pengolah dalam satuan rupiah per kilogram. Berdasarkan data yang diperoleh, maka dilakukan analisis data yaitu data tentang nilai tambah, jumlah tenaga kerja (HOK), jumlah bahan baku (kg), usia pengolah (tahun), harga output (rp/kg), dan lama usaha (tahun). Faktor-faktor yang mempengaruhi nilai tambah pengolahan ikan manyung asap dapat diketahui dengan menggunakan analisis regresi dengan pendekatan model fungsi produksi Cobb-Douglas, dimana data ditransformasikan ke dalam bentuk logaritma naturalis (ln). Selanjutnya pengolahan data dengan menggunakan program SPSS 16. Adapun hasil regresi faktor-faktor yang mempengaruhi nilai tambah pengolahan ikan manyung asap terperinci pada Tabel 4. Berdasarkan hasil pengujian, model regresi ini sudah terbebas dari masalah multikolinearitas, heteroskedastisitas, 
normalitas dan autokorelasi mempengaruhi nilai tambah (Widarjono, 2009). Adapun model pengolahan ikan manyung asap di persamaan regresi dengan tetap Kabupaten Demak adalah variabel melibatkan variabel yang tidak jumlah tenaga kerja, jumlah bahan berpengaruh dalam model adalah:

Ln NT $=-168,127+0,159 \ln X_{1}+0,199$ baku, usia pengolah, dan harga output. $\ln X_{2}-0,474 \ln X_{3}+17,302 \ln$ $\mathrm{X}_{4}+0,084 \ln \mathrm{X}_{5}+\mu$

Adapun faktor - faktor yang Sementara variabel lama usaha, berpengaruh tidak signifikan terhadap nilai tambah pengolahan ikan manyung asap.

Tabel 4. Hasil Analisis Regresi Faktor-Faktor Yang Mempengaruhi Nilai Tambah Pengolahan Ikan Manyung Asap Di Kabupaten Demak

\begin{tabular}{llrrr}
\hline No & \multicolumn{1}{c}{ Variabel } & $\begin{array}{c}\text { Koefisien } \\
\text { Regresi }\end{array}$ & t-hitung & Signifikansi \\
\hline 1 & Konstanta & $-168,127^{* * *}$ & $-24,498$ & 0,0000 \\
2 & Jumlah Tenaga kerja & $0,159^{*}$ & 1,693 & 0,095 \\
3 & Jumlah Bahan Baku & $0,199^{* * *}$ & 3,731 & 0,000 \\
4 & Usia pengusaha & $-0,474^{* * *}$ & $-2,940$ & 0,005 \\
5 & Harga Output & $17,302^{* * *}$ & 25,053 & 0,000 \\
6 & Lama usaha & 0,084 ns & 1,488 & 0,142 \\
\hline 7 & R-squared & 0,927 & \\
8 & Adjusted R-squared & 0,921 & $0,000^{a}$ \\
9 & F- hitung & 161,359 & Sig. F-hitung \\
10 & F tabel 1\% & 3,34 & & \\
11 & t tabel 1\% & 2,660 & & \\
12 & t tabel 5\% & 2,000 & \\
13 & t tabel 10\% & 1,671 & \\
14 & Durbin-Watson stat & 1,632 & \\
\hline Keterangan: * signifikan pada tingkat kepercayaan 90\% $(\alpha=0,10)$ \\
** signifikan pada tingkat kepercayaan 95\% $(\alpha=0,05)$ \\
*** signifikan pada tingkat kepercayaan 99\% $(\alpha=0,01)$ \\
ns tidak signifikan
\end{tabular}

Sumber: Analisis Data Primer, 2018.

\section{SIMPULAN}

Usaha pengolahan ikan manyung asap memberikan nilai tambah sebesar Rp.4.042/kg dengan rasio nilai tambah 14,58\%. Tingkat kelayakan usaha per siklus produksi pengolahan ikan manyung asap; BEP produksi 16,442 $\mathrm{kg}$, BEP penerimaan Rp.358.604, RC ratio 1,154 dan keuntungan Rp.251.908. Faktor-faktor yang mempengaruhi nilai tambah pengolahan ikan asap adalah variabel jumlah tenaga kerja, jumlah bahan baku, usia pengolah, dan harga output.

\section{Ucapan Terimakasih}

Penulis mengucapkan Terimakasih banyak kepada Kementerian Ristekdikti yang sudah mendanai penelitian ini, untuk tahun anggaran 
2018, serta kepada mahasiswa (Haniatul Mar'umah, Amin Soleh, Lusiana Kurniasari serta Hasan Anwar) yang sudah turut membantu di lapangan. Tidak lupa kepada Fakultas Pertanian Universitas Wahid Hasyim Semarang, keluarga beserta beberapa pihak yang tidak dapat penulis sampaikan satu persatu, yang terlibat dalam penelitian ini, sehingga penelitian dapat dilaksanakan.

\section{DAFTAR PUSTAKA}

Anonim. (2012). Peresmian Sentra Ikan Asap Di Kabupaten Demak Tahun 2012.

http://www.djpdspkp.kkp.go.id/arti kel-704-peresmian-sentra-ikanasap-di-kabupaten-demak-tahun2012.html. Humas Ditjen PDSPKP. Direktorat Jenderal Penguatan daya saing Produk kelautan dan Perikanan RI. Menteri kelautan dan Perikanan RI. Diakses pada hari Senin tanggal 13 Agustus 2018.

BPS. 2016. Kabupaten Demak Dalam Angka 2016. BPS (Badan Pusat Statistika) Kabupaten Demak. Demak.

Hayami, Y. et. all. 1987. Agricultural Marketing and Processing in Upland Java; A Perspektif From A Sunda Village. CGPRT No 8. Bogor.

Kementerian Kelautan dan Perikanan. 2011, Statistik Kelautan dan Perikanan 2010, Kementerian Kelautan dan Perikanan, Jakarta.
Shoimah, H. Hartuti Purnaweni, dan Bambang Yulianto. 2013. Pengelolaan Lingkungan di Sentra Pengasapan Ikan Desa Wonosari Kecamatan Bonang Kabupaten Demak. Prosiding Seminar Nasional Pengelolaan Sumberdaya Alam dan Lingkungan. Ilmu Lingkungan Universitas Diponegoro. Semarang.

Soekartawi. 2002. Analisis Usaha Tani. Jakarta. UI-Press.

Sulistijowati, Rieny., dkk. 2011. Mekanisme Pengasapan Ikan. UNPAD Press. Bandung.

Sulistyowati, R. Pramono, Karyadi. 2010. Analisis Finansial Dan Pendapatan Usaha Pengasapan Ikan 'Mina Asri' Rumah Tangga Di Kelurahan Tanjung Mas Kecamatan Semarang Utara Kota Semarang. Agromedia. Vol. 28 (2). Agustus 2010. 73-81.

Suratiyah, K. (2015). Ilmu Usahatani (Edisi Revisi). Jakarta: Penebar Swadaya.

Tasman, A dan Aima, M.H. 2013. Ekonomi Manajerial. Raja Wali Pers. Jakarta.

Widarjono, Agus. 2009. Ekonometrika Pengantar Dan Aplikasinya. Ekonisia. UII. Yogyakarta.

Yusroni, Nanang. 2009. Analisis Profit Margin Untuk Meningkatkan Nilai Tambah Pendapatan Antar Pengrajin Pengasapan Ikan Manyung, Ikan Tongkol dan Ikan Pari Di Bandarharjo Semarang. Akses Jurnal Ekonomi dan Bisnis. Vol. 4 (8). Oktober. Hal 139-148. Fakultas Ekonomi Universitas Wahid Hasyim. Semarang. 